See Article page XXX.

\section{Commentary: An oldie is not always a goodie}

\author{
Joseph S. Coselli, MD
}

Acute DeBakey type I aortic dissection remains a surgical emergency that necessitates cardiopulmonary bypass. The best arterial cannulation access point for bypass inflow continues to be a matter of debate. Wang and colleagues ${ }^{1}$ at the Beijing Hazion Hospital attempt to resolve this controversy by reviewing their extensive experience in the treatment of DeBakey type I aortic dissection using axillary artery cannulation and comparing it to femoral artery cannulation, and in most cases, comparing it a combined strategy using femoral and axillary artery cannulation. The authors' operative strategy included the standard use of hypothermic circulatory arrest while providing unilateral antegrade cerebral perfusion. The 2014 European Society of Cardiology guidelines $^{2}$ recommend the right axillary artery as the primary choice for cannulation of DeBakey type I aortic dissection and notes that previous studies found that femoral artery cannulation was associated with an elevated risk of stroke in such patients. Furthermore, De Paulis and colleagues ${ }^{3}$ conducted a European survey on surgeons' operating preference and discovered that $91 \%$ of those responding used antegrade cerebral perfusion, either unilateral or bilateral, in acute aortic dissection. And for arterial cannulation, the

\footnotetext{
From the Division of Cardiothoracic Surgery, Michael E. DeBakey Department of Surgery, Baylor College of Medicine, Houston, Tex; Section of Adult Cardiac Surgery, Department of Cardiovascular Surgery, Texas Heart Institute, Houston, Tex; and CHI St Luke's Health-Baylor St Luke's Medical Center, Houston, Tex.

The Cullen Foundation did not provide formal support for this project. The support endowed chair.

Disclosures: Dr Coselli consults for, receives royalties and a departmental educational grant from, and participates in clinical trials for Terumo Aortic; consults and participates in clinical trials for Medtronic Inc, Edwards Lifesciences, CryoLife, and W.L. Gore \& Associates; and serves as a coinvestigator for CytoSorbents.

The Journal policy requires editors and reviewers to disclose conflicts of interest and to decline handling or reviewing manuscripts for which they may have a conflict of interest. The editors and reviewers of this article have no conflicts of interest.

Received for publication Dec 21, 2021; revisions received Dec 21, 2021; accepted for publication Dec 22, 2021.

Address for reprints: Joseph S. Coselli, MD, Division of Cardiothoracic Surgery, Michael E. DeBakey Department of Surgery, Baylor College of Medicine, One Baylor Plaza, BCM 390, Houston, TX 77030 (E-mail: jcoselli@bcm.edu).

J Thorac Cardiovasc Surg 2022; $\mathbf{\square}: 1-2$

0022-5223/\$36.00

Copyright (c) 2021 by The American Association for Thoracic Surgery

https://doi.org/10.1016/j.jtcvs.2021.12.043
}

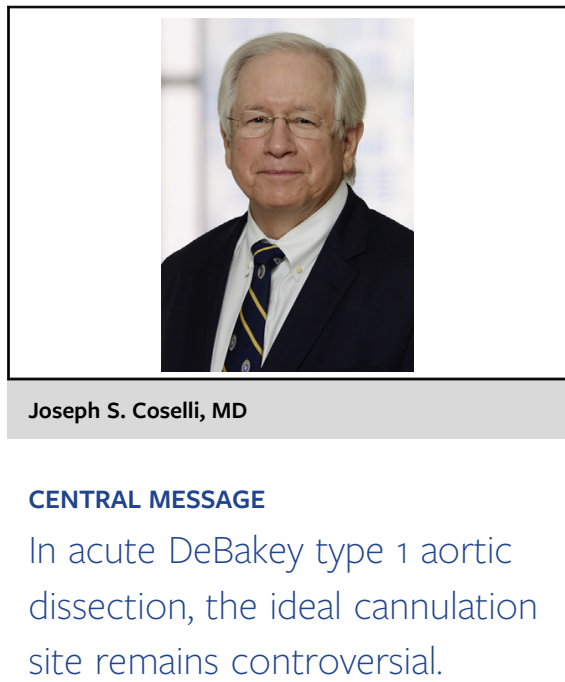

right axillary artery was a first choice for $54 \%$ of surgeons, followed by the choice of femoral artery by $28 \%$.

In this work by Wang and colleagues, ${ }^{1}$ the authors focused on repairs involving the frozen elephant trunk method of total arch replacement for which they treated 1522 patients between 2009 and 2019. Eight patients were excluded from this retrospective analysis because of an alternate cannulation strategy, and of those, 7 underwent innominate artery cannulation and 1 underwent ascending aortic cannulation. At our institution, we have reported on our extensive experience with innominate artery cannulation, which has become our preferred technique. ${ }^{4-6}$ Wang and colleagues ${ }^{1}$ performed propensity score matching on patients with axillary artery-only cannulation and femoral artery cannulation. In 439 patients, the femoral artery was used as a site of arterial cannulation; however, 333 of these patients received both axillary combined with femoral artery cannulation, and only 106 of these patients received isolated femoral artery cannulation. Thus, the authors performed two propensity score matching analyses: isolated axillary artery cannulation was first compared to any form of femoral artery cannulation (ie, isolated or combined use) and then compared to the combined axillary-femoral artery cannulation strategy. Wang and colleagues ${ }^{1}$ concluded that the risk of stroke was increased when either type of femoral artery cannulation was used and that operative mortality and the rate of 30-day death were also increased in the combined axillary-femoral artery group. They also concluded that femoral artery 
cannulation was an independent risk factor for in-hospital mortality, 30-day mortality, and stroke.

The authors appropriately point out that femoral artery cannulation risks retrograde embolization of atheroma and calcified plaques. Additionally, this technique has been associated with malperfusion and pressurization of the false lumen. The clear advantages of axillary artery cannulation, such as a decreased risk of stroke from emboli, reduced incidence of malperfusion, and establishing a bloodless operating field, as well as facilitating the use of antegrade cerebral perfusion. The authors argue that understanding the operative risks of using femoral artery cannulation has been hampered by varied techniques used within a given series, such as the type of hypothermia provided (ie, mild, moderate, or deep), antegrade versus retrograde cerebral perfusion, and unilateral versus bilateral cerebral perfusion. In their own series, the authors resolve this heterogenity by presenting a standard operative strategy for cerebral perfusion, hypothermic temperature, and technique. They rightfully point out that femoral artery cannulation is more commonly used in patients who are critically ill and hemodynamically unstable and who need emergency cardiopulmonary bypass. The authors mention that patients with extremely high body weight may benefit from a femoral artery cannulation, because of the need for higher flows than can be provided using the axillary artery. Sabik and colleagues ${ }^{7}$ introduced axillary artery cannulation more than 2 decades ago, and its use has been widely adopted.

This is a very important article because it supports the use of axillary artery cannulation in even the most complicated aortic repairs, namely those to treat DeBakey type I acute aortic dissection. If it is successful in complex cases, we must rationalize that itworks in simpler cases as well. In our own experience, we have extensively used axillary artery cannulation; however, we now view innominate artery cannulation as our preferred site, although its use is not feasible if dissection has dammaged the artery. ${ }^{4,6}$ Although the authors do not mention it, there is a scenario that occurs in which femoral artery cannulation as an adjunct to axillary artery cannulation may be appropriate. Patients who present with malperfusion and peripheral and leg ischemia are good candidates for both axillary and femoral artery cannulation. Although femoral artery cannulation has been used for decades, it may be necessary to limit its use to that which is absolutely necessary to address patient-specific complications.

\section{References}

1. Wang X, Liu N, Wang H, Liu Y, Sun L, Zhu J, et al. Femoral artery cannulation increases the risk of postoperative stroke in patients with acute DeBakey I aortic dissection. J Thorac Cardiovasc Surg. 2022. XX:XX-X.

2. Erbel R, Aboyans V, Boileau C, Bossone E, Bartolomeo RD, Eggebrecht H, et al. 2014 ESC guidelines on the diagnosis and treatment of aortic diseases: document covering acute and chronic aortic diseases of the thoracic and abdominal aorta of the adult task force for the diagnosis and treatment of aortic diseases of the European Society of Cardiology (ESC). Eur Heart J. 2014;35:2873-926.

3. De Paulis R, Czerny M, Weltert L, Bavaria J, Borger MA, Carrel TP, et al. Current trends in cannulation and neuroprotection during surgery of the aortic arch in Europe. Eur J Cardiothorac Surg. 2015;47:917-43.

4. Preventza O, Price MD, Spiliotopoulos K, Amarasekara HS, Cornwell LD, Omer S, et al. In elective arch surgery with circulatory arrest, does the arterial cannulation site really matter? A propensity score analysis of right axillary and innominate artery cannulation. J Thorac Cardiovasc Surg. 2018;155: 1953-60.e4.

5. Coselli JS, Preventza O. Options for arterial cannulation to provide antegrade cerebral perfusion: everything old is new again. J Thorac Cardiovasc Surg. 2016; 151:1079-80.

6. Preventza O, Garcia A, Tuluca A, Henry M, Cooley DA, Simpson K, et al. Innominate artery cannulation for proximal aortic surgery: outcomes and neurological events in 263 patients. Eur J Cardiothorac Surg. 2015;48:937-42.

7. Sabik JF, Lytle BW, McCarthy PM, Cosgrove DM. Axillary artery: an alternative site of arterial cannulation for patients with extensive aortic and peripheral vascular disease. J Thorac Cardiovasc Surg. 1995;109:885-90. 